\title{
Services quality assessment of Indian Higher Education Institutes
}

\section{BAXIS PATEL}

Received : 28.01.2016; Revised : 11.02.2016; Accepted : 12.03.2016

\begin{abstract}
Higher education in India is governed by the University Grants Commission, which enforces its standards, advises the government and helps co-ordinate between the centre and the state. In India higher education institutions are looking forward of improvements in service quality to satisfy the expectations of their students and the society. Hence, education is a part of service sector and managing services is difficult than managing the goods. India must use the market driven more and more to improve quality in education and largely in the private professional education system, with the state ensuring public assessment so parents and students decide which institutes are of adequate quality to pursue the degree. Here research has tried to identify satisfaction of students from educational institutes. Data were collected from BBA students by undertaking quota sampling method with the help of adapted SERVQUAL statements of expectations only. Here this adapted tool comprises of tangibility, reliability, responsiveness, assurance and empathy aspect of services. Here descriptive statistics were used to report analysis. Present research contributes to the existing pool of knowledge on the relationship between demographic variables of respondents and their expectations and perception of services, other than teaching, from higher education.
\end{abstract}

KEY WORDS : Higher Education Institutes, Services quality, SERVQUAL

How to cite this paper : Patel, Baxis (2016). Services quality assessment of Indian Higher Education Institutes. Internat. J. Com. \& Bus. Manage, 9(1) : 8-16. 